\title{
Problemas de comunicação entre cetáceos e outros mamíferos
}

[Problems in cetacean and other mammalian communication

\section{Gregory Bateson}

A primeira versão deste artigo, publicada em 1966 pela editora da Universidade da Califórnia no capítulo 25 do livro Whales, dolphins and porpoises (editado por Kenneth S. Norris), foi republicada no célebre livro de Gregory Bateson Steps to an ecology mind, que teve sua última publicação pela Universidade de Chicago, no ano 2000. Embora haja divergência mínima entre o original e a publicação mais recente, os tradutores se baseiam na última versão para esta tradução.

Tradução: Lucas Lima, Pedro Crepaldi Carlessi e Joana Cabral de Oliveira

BATESON, Gregory. Problemas de comunicação entre cetáceos e outros mamíferos. Revista do Instituto de Estudos Brasileiros, Brasil, n. 69, p. 465-477, abr. 2018.

DOI: http://dx.doi.org/Io.II606/issn.23I6-90IX.voi69p465-477

I Biólogo e antropólogo (Inglaterra, I904-EUA, I980). 


\section{A COMUNICAÇÃO PRÉ-VERBAL DOS MAMÍFEROS}

Tenho adquiro alguma experiência sobre cetáceos. Uma vez, no Laboratório Zoológico de Cambridge, dissequei uma espécie de Phocoena comprada de um pescador local, e até esse ano não havia encontrado cetáceos novamente, quando tive a oportunidade de encontrar os golfinhos do dr. Lilly. Espero que a discussão de algumas das indagações que estão em minha mente, ao me aproximar desses mamíferos peculiares, ajudem vocês a examinar estas questões ou assuntos relacionados.

Meu trabalho anterior nos campos da antropologia, etologia animal e teoria psiquiátrica me forneceram um modelo teórico para uma análise transacional do comportamento. As premissas dessa posição teórica podem ser brevemente resumidas: I) o relacionamento entre dois (ou mais) organismos é, de fato, uma sequência de $\mathrm{E}-\mathrm{R}^{2 \mathrm{NTI}}$ (por exemplo, o contexto no qual o protoaprendizado ocorre); 2) a deuteroaprendizagem (por exemplo, aprender a aprender) é, de fato, a aquisição de informações sobre padrões de contingência dos contextos nos quais a protoaprendizagem ocorre; e 3) o "caráter" do organismo é o agregado de seu deuteroaprendizado e, portanto, reflete os padrões contextuais da protoaprendizagem passada ${ }^{3}$.

Essas premissas são essencialmente uma estrutura hierárquica da teoria da aprendizagem alinhada à Teoria dos Tipos Lógicos de Russel ${ }^{4}$. As premissas, segundo a Teoria dos Tipos, são primariamente apropriadas para análise da comunicação digital, de modo que estendê-la à comunicação analógica ou a um sistema que combine a analógica com a digital é problemático. Espero que o estudo da comunicação dos golfinhos venha a esclarecer esses problemas fundamentais. A questão não é descobrir se os golfinhos têm uma linguagem complexa ou ensinar-lhes inglês, mas fechar lacunas do nosso conhecimento teórico da comunicação estudando um sistema

2 Sequência behaviorista de estímulos (E) e respostas (R). Ao compreender o estímulo e a resposta como unidades básicas e ponto de partida para que seja possível realizar uma ciência do comportamento, o behaviorismo toma como pressuposto que essas unidades não podem ser entendidas separadamente. (N. do T.)

3 RUESCH, J; BATESON, G. Communication: the social matrix of psychiatry. Nova York: Norton, I95I.

4 WHITEHEAD, A. N; RUSSELL, B. Principia mathematica. London: Cambridge University Press, I9Io. 
que, seja ele rudimentar ou complexo, é quase certo que seja de um tipo totalmente não familiar.

Deixe-me iniciar pelo fato do golfinho ser um mamífero. Este fato tem, é claro, todos os tipos de implicações anatômicas e fisiológicas, mas não é nisso que estou interessado. O que me interessa é a comunicação dos golfinhos, aquilo que é chamado de "comportamento" e que é visto como um agregado de dados perceptíveis e significativos para outros membros da mesma espécie. Significativo, em primeiro lugar, no sentido de que afeta o comportamento de um animal receptor e, em segundo, no sentido de que a falha perceptível para alcançar o significado apropriado no primeiro sentido afetará o comportamento de ambos os animais. O que falo a vocês pode ser completamente ineficiente, mas minha ineficiência, se perceptível, irá nos afetar. Reforço esse ponto porque deve ser recordado que em todas as relações entre o homem e algum outro animal, especialmente se esse animal é um golfinho, uma grande proporção do comportamento de ambos os organismos é determinada por esse tipo de ineficiência.

Quando visualizo o comportamento dos golfinhos como uma forma de comunicação, o rótulo de mamífero implica, para mim, algo muito definido. Deixe-me ilustrar o que eu tenho em mente com um exemplo de Benson Ginsburg sobre uma alcateia no zoológico de Brookfied.

Entre os Canidae, o desmame é realizado pela mãe. Quando o filhote pede para mamar, com sua boca aberta ela pressiona o dorso do pescoço dele para baixo, esmagando-o até o chão. A mãe faz isso repetidamente até o filhote parar de pedir. Esse método é usado pelos coiotes, cães selvagens australianos ${ }^{5}$ e pelo cão doméstico. Entre os lobos o sistema é diferente. Os filhotes passam suavemente do mamilo para o alimento regurgitado. Quando a alcateia retorna à toca saciada, todos regurgitam o que foi apanhado e em seguida comem juntos. Em algum momento, os adultos começam a desmamar os filhotes dessas refeições, usando o método empregado por outros Canidae: com a sua boca aberta, o adulto pressiona para baixo o dorso do pescoço do filhote. Entre os lobos essa função não é restrita à mãe, mas realizada por adultos de ambos os sexos.

O líder da alcateia de Chicago é um magnífico macho que patrulha sem descanso o território em que estão confinados. Ele se move em um trote que parece incansável, enquanto os outros oito ou nove membros da alcateia passam a maior parte do tempo cochilando. Quando as fêmeas estão no cio, elas geralmente se insinuam ao líder batendo contra ele com a parte traseira do corpo. Entretanto, geralmente o líder não responde, porém, evita que outros machos se aproximem. No último ano um dos machos desse bando conseguiu cruzar com uma fêmea. Assim como outros Canidae, o lobo macho fica preso à fêmea, incapaz de livrar seu pênis, ficando assim indefeso. Logo veio o líder da matilha. O que aconteceu com o macho que ousou infringir as prerrogativas do líder? $\mathrm{O}$ antropomorfismo sugeriria que ele dilaceraria o macho indefeso em pedaços. Mas não. A cena mostra que ele pressiona para baixo por quatro vezes a cabeça do macho ousado com sua mandíbula aberta e então simplesmente vai embora.

5 Dingos ou, do original em inglês, "dingoes". (N. do T.) 
Quais são as implicações dessa ilustração para a pesquisa? O que o líder da matilha faz é indescritível, ou apenas insuficientemente descrito em termos de E-R. Ele não apenas "reforça negativamente" a atividade sexual do outro macho, mas confirma ou afirma a natureza da sua relação com os demais. Se tivéssemos que traduzir a atitude do líder da matilha, as palavras "não faça isso" não seriam elas. Muito pelo contrário, elas traduziriam de forma metafórica: "Eu sou o seu macho sênior, filhote!”. O que estou tentando dizer particularmente sobre os lobos, e sobre uma linguagem mamífera pré-verbal no geral, é que seu discurso é primariamente sobre as regras e contingências do relacionamento.

Deixe-me trazer um exemplo mais familiar para tornar a generalidade desse ponto de vista mais íntima a vocês, já que não se trata de uma questão tão ortodoxa entre os etnólogos. Quando sua gata está tentando dizer a você que ela está querendo comida, como ela faz? Ela não possui palavras para comida ou leite. O que ela faz é executar movimentos e sons que são, caracteristicamente, aqueles que um filhote faria à sua mãe. Se tivéssemos que traduzir a mensagem da gata em palavras, não seria correto dizer que ela está choramingando “Leite!”. Pelo contrário, ela está dizendo algo como “Ma-ma!”. Ou, talvez, de forma mais adequada, poderíamos dizer que ela está indicando “Dependência! Dependência!”. O gato fala em termos de padrões e contingências de relacionamento, e cabe a você dar um passo dedutivo a essa fala, supondo que o gato quer leite. $\hat{E}$ a necessidade desse passo dedutivo que marca a diferença entre a linguagem de comunicação pré-verbal dos mamíferos e, igualmente, a comunicação de abelhas e a linguagem dos homens.

O que foi extraordinário - a grande novidade - na evolução da linguagem humana não foi a descoberta da abstração ou generalização, mas a descoberta de como ser específico sobre algo para além da relação. Na verdade, essa descoberta, embora tenha sido alcançada, tem afetado apenas o comportamento sobre os seres humanos. Se A diz para B "O avião está marcado para decolar às 6h3o", B raramente aceita essa proposição como uma mera afirmação sobre o avião. Ele dedica, habitualmente, alguns neurônios a essa questão e pensa: "o que a fala de A me indica sobre a minha relação com A?”. Nossa ancestralidade mamífera está muito próxima à superfície apesar dos truques linguísticos adquiridos recentemente.

Seja como for, minha primeira expectativa em estudar a comunicação dos golfinhos é que ela provará que a característica geral dos mamíferos está, principalmente, nos relacionamentos. Talvez essa premissa seja em si suficiente para explicar o desenvolvimento esporádico de grandes cérebros entre mamíferos. Não precisamos reivindicar que, embora elefantes não falem e baleias não inventem artimanhas verbais, essas criaturas não sejam notoriamente inteligentes. Tudo o que importa é supor que criaturas com enormes cérebros foram, em algum estágio da cadeia evolutiva, ininteligentes o suficiente para entrarem no jogo do relacionamento e assim, uma vez que a espécie foi capturada nesse jogo de interpretação mútua de comportamentos relevantes de seus membros para assuntos complexos e vitais, havia um valor de sobrevivência para aqueles indivíduos que pudessem jogar com grande ingenuidade ou grande sabedoria.

Podemos, então, esperar encontrar uma complexidade bastante alta na comunicação que envolve o relacionamento entre os cetáceos. Por serem mamíferos, 
podemos esperar que a comunicação deles seja primordialmente em termos de padrões e contingências de relacionamento. Pelo fato ${ }^{6}$ de serem animais sociais e com enormes cérebros, poderíamos esperar uma alta complexidade em suas comunicações.

\section{Considerações metodológicas}

As hipóteses acima introduzem dificuldades muito peculiares sobre como testar aquilo que é chamado de "psicologia" (por exemplo, inteligência, ingenuidade, discriminação etc.) dos indivíduos animais. Um simples experimento discriminatório, como o que ocorreu nos laboratórios Lilly, e sem dúvida em outros locais, envolve viárias etapas: I) o golfinho pode ou não perceber a diferença entre objetos de estímulo X e Y; 2) o golfinho pode ou não perceber que a diferença é um indicativo para um comportamento; 3) o golfinho pode ou não perceber que o comportamento em questão tem um bom ou mau efeito sobre o reforço, ou seja, que fazer o "certo" é seguido condicionalmente por receber um peixe; e 4) o golfinho pode ou não escolher fazer o "certo", mesmo ele sabendo qual a opção correta. O sucesso nas três primeiras etapas apenas fornece ao golfinho uma outra possibilidade de escolha. Esse grau extra de liberdade deve ser nosso principal foco de investigação.

Deve ser nosso primeiro foco por razões metodológicas. Considere os argumentos que são convencionalmente baseados em experimentos desse tipo. Sempre discutimos da última etapa à primeira. Dizemos: "se em nosso experimento o animal foi capaz de compreender o passo 2, então ele foi capaz de compreender o passo I”. Se ele pode entender que se comportando de tal maneira lhe é garantida alguma recompensa, então ele tem uma acuidade sensorial de discriminar entre $\mathrm{X}$ e $\mathrm{Y}$ e, muito mais.

Por desejarmos argumentar exatamente a partir da observação do sucesso animal, desde os últimos passos em direção às conclusões até as etapas mais elementares, torna-se de primordial importância sabermos se o organismo com o qual estamos lidando é capaz do passo 4. Se for capaz, então todos os argumentos sobre os passos de I a 3 serão invalidados, a menos que métodos apropriados de controle do passo 4 estejam incorporados no projeto experimental. Curiosamente, embora o ser humano seja totalmente capaz do passo 4, os psicólogos que trabalham com questões humanas têm sido capazes de estudar as fases de I a 3 sem tomarem o devido cuidado de excluírem as confusões geradas por esse fato. Se o sujeito humano é "cooperativo e são", ele geralmente responde à situação testada reprimindo a maioria de seus impulsos para modificar seu comportamento de acordo com o seu ponto de vista sobre o seu relacionamento com o experimentador. As palavras cooperativo e são implicam um grau de consistência da etapa 4. O psicólogo opera por um tipo de petitio principii: se o sujeito é cooperativo e são (isto é, se as regras de relacionamentos são

6 O autor utiliza o neologismo "be-cause", ressaltando a interação e atenuando a causalidade entre expressão corporal/verbal, comunicação pré-verbal/pós-verbal, causa/efeito, da qual a tradução para o português se mostra insuficiente. (N. do T.) 
realmente constantes), o psicólogo não necessita se preocupar sobre mudanças nessas regras.

O problema do método torna-se completamente diferente quando o sujeito é não cooperativo, psicopata, esquizofrênico, uma criança desobediente ou um golfinho. Talvez a característica mais fascinante desse animal se derive precisamente de sua habilidade de operar em níveis relativamente altos, uma habilidade que está ainda por ser demonstrada.

Deixe-me agora considerar por um momento a arte do treinador de animais. Em conversas com essas pessoas altamente habilidosas - treinadores de golfinhos e de cães-guia -, minha impressão é que o primeiro requisito de um treinador está em sua capacidade de prevenir que o animal exerça escolhas de nível 4. Deve ficar continuamente claro para o animal que, quando ele reconhece que está fazendo a coisa certa dentro de determinado contexto, isso é a única coisa que ele pode fazer, sendo que nenhuma insensatez deve haver sobre isso. Em outras palavras, uma condição primordial de sucesso dos circos é que o animal revogue o uso de níveis elevados de sua inteligência. A arte do hipnotizador é similar.

Existe uma história contada sobre o dr. Samuel Johnson. Uma senhora estúpida fez seu cachorro executar alguns truques em sua presença. $O$ doutor pareceu não se impressionar. A senhora então disse: "mas doutor, você não sabe o quão difícil é para o cão”. Dr. Johnson replicou: “difícil, senhora, seria se fosse impossível!”.

O que é interessante sobre truques de circo é que o animal pode revogar o uso de sua inteligência e ainda ser capaz de executar um truque. Considero a inteligência consciente como um dos grandes ornamentos da mente humana. Todavia, muitas autoridades, desde os mestres zen até Sigmund Freud, enfatizam a ingenuidade do nível menos consciente e talvez mais arcaico.

\section{COMUNICAÇÃo SOBRE RELACIONAMENTOS}

Como havia dito anteriormente, espero que a comunicação dos golfinhos seja quase totalmente de um tipo não familiar. Permitam-me aprofundar este ponto. Como mamíferos, estamos familiarizados, embora em grande parte inconscientemente, com o hábito de nos comunicar sobre nossos relacionamentos. Assim como outros mamíferos terrestres, realizamos a maior parte de nossa comunicação através de sinais cinésicos e paralinguísticos, tais como movimentos corporais, tensões involuntárias de músculos voluntários, mudanças de expressão facial, hesitações, mudanças no ritmo da fala ou do movimento, tons de voz e irregularidades na respiração. Se você quer compreender o que o latido de um cão "significa”, observe seu focinho, os pelos sobre o pescoço, seu rabo etc. Essas "expressivas” partes de corpo do cão dizem a você qual o objetivo do latido, e quais padrões de relacionamento ele está suscetível a seguir nos próximos segundos. Acima de tudo, você observa os seus órgãos dos sentidos: seus olhos, ouvidos e nariz.

Em todos os mamíferos os órgãos dos sentidos também se tornaram órgãos de transmissão de mensagens sobre relacionamentos. Um cego nos deixa desconfortável não porque ele não é capaz de ver, o que é o seu problema e nós somos apenas 
vagamente cientes disso, mas pelo fato de ele não nos transmitir, através do movimento de seus olhos, as mensagens que esperamos e precisamos para sabermos e termos certeza do estado de nossa relação com ele. Não entenderemos muito sobre a comunicação dos golfinhos até que saibamos o que um golfinho pode ler no uso, direção, volume e altura da ecolocalização de outro indivíduo.

Talvez seja essa ausência em nós que faz a comunicação dos golfinhos parecer misteriosa e opaca, todavia, suponho uma explicação mais profunda. A adaptação à vida no oceano tem destituído a expressão facial das baleias. Elas não têm orelhas externas para mexer e possuem poucos - ou nenhum - pelos eréteis. Mesmo as vértebras cervicais são fundidas em um bloco sólido em muitas espécies, e a evolução tem aperfeiçoado o corpo, sacrificando a expressividade das partes separadas para a locomoção do todo. Além disso, mesmo que um golfinho tivesse um rosto móvel, as condições de vida no mar são tais, que os detalhes de sua expressão seriam visíveis para os outros indivíduos apenas a uma distância bastante curta, até em águas mais claras.

É razoável, então, supor que nesses animais a vocalização tenha assumido as funções comunicativas que a maioria dos animais executa por expressão facial, abanando a cauda, punhos cerrados, mãos supinadas, narinas alargadas, entre outros. Podemos dizer que a baleia é o oposto comunicacional da girafa: não tem pescoço, mas possui voz. Esta especulação por si só tornaria a comunicação dos golfinhos um tema de grande interesse teórico. Seria fascinante, por exemplo, saber se a mesma estrutura geral de categorias é ou não mantida em uma mudança evolutiva da comunicação cinésica para a vocalização.

Minha impressão pessoal - e é apenas uma impressão, sem testes que a embasem é que a hipótese de que os golfinhos substituíram a paralinguística pela comunicação cinésica não se encaixa perfeitamente em minha experiência quando escuto seus sons. Nós, mamíferos terrestres, estamos familiarizados com a comunicação paralinguística; usamo-la em grunhidos e gemidos, risos e soluços, modulações da respiração enquanto falamos e assim por diante. Portanto, não achamos os sons paralinguísticos de outros mamíferos totalmente opacos. Aprendemos com bastante facilidade a reconhecer neles certos tipos de saudação, afetividade, raiva, persuasão e territorialidade, embora nossas suposições muitas vezes possam estar erradas. Mas quando ouvimos os sons dos golfinhos não somos sequer capazes de adivinhar seu significado. Eu não confio muito no palpite que explicaria os sons dos golfinhos como meramente uma elaboração da paralinguística de outros mamíferos. (Argumentar dessa maneira sobre nossa incapacidade é, no entanto, mais fraco do que argumentar a partir do que podemos fazer.)

Pessoalmente, não acredito que os golfinhos possuam alguma coisa que um linguista humano chamaria de "linguagem". Não acho que qualquer animal sem mãos poderia ser estúpido o suficiente para chegar a um modo tão bizarro de comunicação.

Usar uma sintaxe e um sistema categorial apropriado para discussões de assuntos que possam ser processados, enquanto realmente se discutem os padrões e contingências de relacionamento, é fantástico. Mas isso, eu concordo, é o que está acontecendo nesta sala. Eu estou aqui e falo enquanto vocês escutam e assistem. Tento convencer vocês, fazer vocês verem as coisas ao meu modo, angariar respeito, indicar 
meu respeito a vocês, desafiá-los e muito mais. O que está realmente acontecendo é uma discussão dos padrões de nosso relacionamento, tudo de acordo com as regras de uma conferência científica sobre baleias. Portanto, isso é ser um humano.

Simplesmente não acredito que os golfinhos tenham linguagem nesse sentido. Todavia, creio que, como nós e outros mamíferos, eles estão preocupados com os padrões de seus relacionamentos. Vamos chamar esta discussão dos padrões de relacionamento de a função $t$ da mensagem. Afinal, foi o gato que nos mostrou a grande importância dessa função com o seu miado. Quando necessitam, os mamíferos pré-verbais se comunicam sobre as coisas utilizando principalmente sinais de função $\mu$. Em contraste, os seres humanos usam a linguagem, que é orientada predominantemente para as coisas, para discutir relacionamentos. $O$ gato pode pedir leite dizendo "dependência", e eu peço por sua atenção e talvez respeito procurando falar sobre as baleias. Contudo, não sabemos se os golfinhos, em sua comunicação, se parecem conosco ou com o gato. Eles podem ter um sistema bastante diferente.

\section{CoMUNiCAÇão aNALÓgICA VERSUS COMUNICAÇÃo digitaL}

Há outro lado do problema. Como é que a paralinguística e a comunicação cinésica dos homens de culturas diferentes e até mesmo a paralinguística de outros mamíferos terrestres são ao menos parcialmente inteligíveis para nós, enquanto as linguagens verbais de outras culturas nos parecem totalmente opacas? Nesse aspecto, parece que as vocalizações do golfinho se assemelham mais à linguagem humana do que a cinesia ou a paralinguística dos mamíferos terrestres.

Sabemos, é claro, por que gestos e tons de voz são parcialmente inteligíveis enquanto línguas estrangeiras são ininteligíveis. É porque a linguagem é digital e a comunicação cinésica e a paralinguística são analógicas 7 . A essência da questão é que na comunicação digital vários signos puramente convencionais - I, 2, 3, X, Y, e assim por diante - são impulsionados de acordo com regimes chamados algoritmos. Os signos em si não possuem simples conexões (por exemplo, correspondência de magnitude) com o que representam. O número "5" não é maior que o número " 3 ". É verdade que se removermos o travessão do numeral " 7 " obteremos o numeral "I"; mas o travessão não corresponde, de nenhuma maneira, ao "6". Um nome normalmente tem apenas uma conexão puramente convencional ou arbitrária com a classe nomeada. O numeral " 5 " é somente o nome de uma magnitude. Não faz sentido perguntar se meu número de telefone é maior do que o seu, porque a central telefônica é um computador puramente digital. Ele não é alimentado com magnitudes, mas apenas com nomes de posições em uma matriz.

$\mathrm{Na}$ comunicação analógica, contudo, são usadas magnitudes reais, e elas

7 A diferença entre os modos de comunicação digital e analógica talvez possa ser deixada clara pelo pensamento de um matemático de língua inglesa confrontado com um artigo de um colega japonês. Ele olha para os ideogramas japoneses sem compreender, mas é capaz em parte de entender os gráficos cartesianos na publicação japonesa. Os ideogramas, embora originalmente tenham sido imagens analógicas, são agora puramente digitais; os gráficos cartesianos são analógicos. 
correspondem a magnitudes reais no tema do discurso. O telêmetro vinculado a uma câmera é um exemplo familiar de um computador analógico. Esse dispositivo é alimentado com um ângulo que tem magnitude real e é, de fato, o ângulo que a base do telêmetro encontra em algum ponto sobre o objeto a ser fotografado. Esse ângulo controla um came ${ }^{8}$ que, por sua vez, move a lente da câmera para frente ou para trás. O segredo do dispositivo reside na forma do came, que é uma representação analógica (isto é, uma imagem, um gráfico cartesiano) do relacionamento funcional entre a distância do objeto e a distância da imagem.

A linguagem verbal é quase que (mas não completamente) puramente digital. A palavra "grande" não é maior que a palavra "pequeno"; e em geral não há nada no modelo (isto é, no sistema de magnitudes inter-relacionadas) da palavra "mesa" que corresponderia ao sistema de magnitudes inter-relacionadas do objeto denotado. Por outro lado, na comunicação cinésica e paralinguística a magnitude do gesto, a intensidade da voz, a duração da pausa, a tensão do músculo etc. são magnitudes que costumam corresponder (direta ou inversamente) às magnitudes do relacionamento que é o tema do discurso. O padrão de ação na comunicação do líder da alcateia é imediatamente inteligível quando possuímos dados sobre as práticas de desmame do animal, pois essas práticas são sinais cinésicos analógicos por si mesmos.

Portanto, é sensato considerar a hipótese de que a vocalização dos golfinhos pode ser uma expressão digital de funções $\mu$. É essa possibilidade que tenho em mente quando afirmo que essa comunicação pode ser de um tipo quase totalmente não familiar. $\mathrm{O}$ homem, é verdade, possui poucas palavras em funções $\mu$, palavras como "amor", "respeito", "dependência", e assim por diante. Porém, essas palavras funcionam de forma escassa para a atual discussão do relacionamento entre os participantes na relação. Se você diz a uma garota "eu te amo", provavelmente ela prestará mais atenção na paralinguística e na comunicação cinésica do que nas próprias palavras.

Nós, humanos, ficamos muito desconfortáveis quando alguém começa a interpretar nossas posturas e gestos traduzindo-os em palavras sobre relacionamento. Preferimos muito mais que nossas mensagens sobre esse assunto permaneçam analógicas, inconscientes e involuntárias. Tendemos a não confiar no homem que simula mensagens sobre relacionamentos. Com isso, não temos ideia do que é ser uma espécie com um sistema digital muito simples e rudimentar, cujo tema principal seja funções $\mu$. Esse sistema é algo que nós, mamíferos terrestres, não somos capazes de imaginar e para o qual não temos empatia.

\section{Planos de Pesquisa}

A parte mais especulativa do meu artigo é a discussão dos planos para testar e amplificar tais hipóteses. Eu devo me guiar pelas seguintes suposições heurísticas:

8 Componente mecânico do equipamento. Geralmente é composto por uma superfície excêntrica que produz movimento numa segunda estrutura, que justamente caracteriza o movimento indicado pelo autor. (N. do T.) 
I. A epistemologia, em cujos termos as hipóteses são construídas, não está sujeita a testes. Derivada de Whitehead e Russell, serve para guiar nosso trabalho. Se o trabalho se revelar gratificante, o sucesso será apenas uma fraca verificação da epistemologia.

2. Nós ainda não sabemos qual a aparência de um sistema digital primitivo para a discussão de padrões de relacionamento, mas podemos supor que não se assemelha a uma linguagem "coisa". (Pode ser, provavelmente, semelhante à música.). Portanto, não espero que as técnicas para decompor códigos linguísticos humanos sejam imediatamente aplicáveis à vocalização dos golfinhos.

3. O primeiro requisito, então, é identificar e classificar as variedades e os componentes das relações existentes entre os animais através de um estudo etológico detalhado de suas ações, interações e organização social. Os elementos nos quais esses padrões são construídos estão, indubitavelmente, ainda presentes na cinesia e nas ações da espécie. Portanto, começamos listando os sinais cinésicos de golfinhos individuais para, em seguida, tentarmos relacioná-los aos contextos em que são utilizados.

4. Sem dúvida, assim como o comportamento do líder da alcateia nos informa que a "dominância" entre os lobos está metaforicamente relacionada ao desmame, também os golfinhos nos dirão suas metáforas cinésicas para "dominância", "dependência" e outras funções $\mu$. Gradualmente esse sistema de sinais se encaixará, pedaço por pedaço, para formar um quadro das variedades de relações existentes, mesmo entre animais arbitrariamente confinados juntos em um tanque.

5. Ao começarmos a compreender o sistema de metáforas do golfinho, será possível reconhecer e classificar os contextos de sua vocalização. Neste ponto, as técnicas estatísticas para decodificação de códigos podem tornar-se úteis.

As suposições sobre a estrutura hierárquica do processo de aprendizagem - em que este artigo é baseado - fornecem a base para vários tipos de experimentações. Os contextos de protoaprendizagem podem ser construídos de forma diversa, com vista a observar em quais tipos de contextos certas formas de aprendizagem ocorrem com maior facilidade. Devemos prestar especial atenção aos contextos que envolvem relações entre dois ou mais animais e uma pessoa, ou relações entre duas ou mais pessoas e um animal. Tais contextos são modelos em miniatura de organização social dentro dos quais se espera que o animal mostre comportamentos característicos e faça tentativas particulares de modificar o contexto (isto é, manipular os seres humanos).

9 WHITEHEAD, A. N.; RUSSELL, B., op. cit. 


\section{Comentários}

Mr. Wood - Ao longo de doze anos no Marine Studios na Flórida, passei muito tempo observando o que talvez fosse o mais natural conjunto de Tursiops em cativeiro, incluindo animais de várias idades, normalmente dois ou mais deles em processo de crescimento, e vi muito pouco do que você encontrará em grupos mais restritos nas Ilhas Virgens.

Uma vez eu vi algo muito interessante. Certa manhã, por volta das 6 ou 6 e meia, durante um período de pelo menos meia hora, o macho adulto assumiu uma posição próxima de uma das fêmeas no tanque, que estava estática na correnteza. Ele ia ocasionalmente e se afastava, para depois voltar e assumir uma posição ao lado dela, acariciando sua lateral com a nadadeira direita repetidamente. Não havia indicação de que isso tivesse conotação sexual. Não houve ereção por parte do macho e nenhuma resposta observável por parte da fêmea. Contudo, foi o sinal não vocal mais nítido que eu já observei no tanque.

Mr. Bateson - Gostaria de dizer que a quantidade de sinalização em curso é muito maior do que é evidente à primeira vista. Existem, é claro, os tipos mais específicos de sinais, que são muito importantes. Não estou negando isso. Eu quero dizer o toque, e muito mais. Porém, o indivíduo tímido, a fêmea traumatizada, que permanece quase estacionária a três pés da superfície enquanto outros dois indivíduos brincam, está recebendo uma grande atenção somente por parar lá e ficar. Ela pode não estar ativamente transmitindo, mas nesse negócio de comunicação corporal, você não necessita transmitir sinais ativamente a fim de que sejam apanhados por outras pessoas. Você pode somente ser, e só pelo fato de ser ela atrai uma enorme quantidade de atenção desses dois indivíduos que aparecem, que a ignoram, param um pouco ao passar, e assim por diante. Ela é, poderíamos dizer, "retraída”, mas ela é, na verdade, tão retraída quanto um esquizofrênico, que ao ser retraído se torna o centro de gravidade da família. Todos os outros membros movem-se ao redor do fato de sua retração, que nunca ela os deixa esquecer ${ }^{\text {To }}$.

Dr. Ray - Eu tendo a concordar com Mr. Bateson. Estamos trabalhando no New York Aquarium com a baleia beluga, e eu acredito que esses animais são muito mais expressivos do que nós costumamos suspeitar. Penso que uma das razões de elas ficarem inibidas no cativeiro é pelo fato de estarem constantemente muito entediadas. Não há nada de muito interessante em seu ambiente de tanque, e gostaria de sugerir que temos de manipular o cativeiro delas com muito mais inteligência do que nós fazemos. Não me refiro ao manejo das baleias. Elas não gostam disso. Mas a introdução de diferentes tipos de animais, ou pequenas coisas engenhosas que poderíamos realizar, faria com que respondessem mais. Cetáceos de cativeiros são como macacos em uma jaula. Eles são altamente inteligentes e altamente desenvolvidos, e estão entediados.

Io Na grafia original o autor utiliza o neologismo for-get ("para-obter"), com hífen, reforçando a antítese referida no texto. (N. do T.) 
Outro fator é a nossa habilidade de observação, e na baleia beluga, pelo menos, temos percebido visualmente os sons que fazem ao observarmos a mudança na forma do melão, que é extremamente marcada nesse animal. Ele pode inchar de um lado ou de outro, ou apresentar diversas formas conforme a produção de som. Assim, através de observação cuidadosa e/ou manipulação hábil, acho que um grande negócio pode ser feito com esses animais de forma bastante simples.

Mr. Bateson - Eu quis dizer que todos os órgãos dos sentidos entre os mamíferos, e mesmo entre as formigas, se tornam órgãos importantes para a transmissão de mensagens, como "onde os olhos do companheiro estão focados?" e "seus ouvidos focalizaram em uma direção ou na outra?”. Dessa forma, os órgãos dos sentidos tornam-se órgãos transmissores de sinais.

Se vamos entender golfinhos, uma das coisas que devemos absolutamente adquirir é o conhecimento de que um animal sabe e pode ler a partir da utilização do sonar de outros animais. Eu suspeito a presença de todos os tipos de regras de cortesia nesse negócio; provavelmente não é educado escrutinar em demasia com seu sonar seus amigos, assim como entre os seres humanos não é educado, na verdade, olhar em detalhe os pés do outro. Nós temos muitos tabus em observar uma ou outra cinesia, porque muita informação pode ser obtida dessa forma.

Dr. Purves - Parece-me que o golfinho ou os cetáceos devem sofrer de uma desvantagem ainda maior do que a tida pelo homem no passado, porque - esqueci-me da autoridade - foi dito que a origem da fala humana é uma linguagem analógica. Em outras palavras, se você usar a palavra "para baixo", você abaixa a mão e o maxilar inferior ao mesmo tempo. Se você diz "para cima", você levanta a mão e levanta o maxilar inferior. E se você utiliza a palavra "mesa", e, melhor ainda, a pronuncia em francês, sua boca se alarga e você faz um gesto horizontal. Por mais complicada que seja a linguagem humana, ela tem sua origem numa linguagem analógica. $O$ pobre boto não tem nada disso para começar. Portanto, ele deve ter sido muito inteligente para ter desenvolvido um sistema de comunicação completamente novo.

Mr. Bateson - O que aconteceu a essa criatura é que a informação que obtemos visualmente, assim como outros animais terrestres, deve ter sido impulsionada para a voz. Afirmo ainda que é apropriado para nós começarmos a investigar o que resta do material visual. 
GREGORY BATESON nasceu em I904, na Inglaterra. Antropólogo, dedicou-se principalmente às intersecções com a psiquiatria, ecologia e evolução. $\mathrm{O}$ artigo aqui traduzido foi elaborado pelo autor a partir de sua experiência nas Ilhas Virgens como diretor do laboratório de golfinhos de John Lilly (I962), e sua experiência posterior na Oceanic Foundation, no Havaí, onde estudou os problemas da comunicação dos cetáceos. O texto original integra o livro Steps to an ecology of mind, publicado em I972 pela Ballantine Books, Inc., Nova York, N.Y, uma publicação cronológica dos trabalhos de Gregory Bateson.

\section{REFERÊNCIAS BIBLIOGRÁFICAS}

RUESCH, J.; BATESON, G. Communication: the social matrix of psychiatry. Nova York: Norton, I95I. WHITEHEAD, A. N.; RUSSELL, B. Principia mathematica. Londres: Cambridge University Press, I9IO. 